\title{
NUMERICAL MODELLING OF THE MORPHODYNAMICS OF THE PLOČE GRAVEL BEACH IN RIJEKA
}

Scientific paper

\section{Goran Lončar}

(Received: 2 April 2021; accepted: 30 October 2021)

\author{
University of Zagreb, Faculty of Civil Engineering, Ph.D., Full Professor
}

Corresponding author: goran.loncar@grad.unizg.hr

\section{Filip Kalinić}

Zagreb University of Applied Sciences, Department of Civil Engineering, Teaching Assistant

Dalibor Carević

Faculty of Civil Engineering, University of Zagreb, Ph.D., Associate Professor

Damjan Bujak

Faculty of Civil Engineering, University of Zagreb, Ph.D., Postdoctoral researcher

\begin{abstract}
The morphodynamics of an artificial gravel beach in the Bay of Rijeka (Ploče Beach) was analyzed. The morphological changes of the beach face were monitored through an intense situation of gravitational surface wind waves from the incident SSW direction. A numerical modeling technique was applied, after initially establishing a numerical model for wave deformation. A model for sediment transport was established based on its results. Both models were based on the finite volume method. In addition, the partial contribution of the longshore component of sediment transport was analyzed based on empirical formulae. The modeling results were verified by comparing the positions and amounts of eroded/accumulated material along the beach with the processing of terrain images in the form of point clouds. The erosion and accumulation positions of the beach sediment material, obtained by numerical model simulations, corresponded to the surveyed positions. The total volume of eroded and accumulated material based on terrain image processing corresponded to the model values.
\end{abstract}

Keywords: Numerical model; sediment transport; wind waves. 


\section{INTRODUCTION}

Gravel beaches commonly need nourishment to provide better recreational facilities or expand existing beach capacities. The choice of a hydrodynamically favorable position and appropriate beach material for the gravel beach face should be rational in terms of minimizing the permanent deposition of the beach material and degradation of bottom biocenosis. After the nourishment of the beach, an initial profile is formed that becomes morphologically active (erosion and accumulation) over time, primarily due to the impact of waves. In the cross-section of the beach, the morphodynamics are the most intense in swash zone [1, 2]. A certain part of the eroded material from the swash zone moves to greater depths, where it accumulates or moves further along the longshore direction of the beach [3]. Unlike long beaches, beach rotation, that is, sediment transport from one end of the beach to another, occurs at miniature beaches [4]. The most significant displacements of the beach material occur at the beach edges while the smallest occurs at the center of the beach (beach rotation point). For naturally balanced gravel beaches, periods with a more moderate wave climate occur after periods of intense wave conditions, during which previously eroded and accumulated material is re-drawn to beach [5]. Artificial gravel beaches are at risk of excluding the regeneration-return mechanism of previously eroded beach materials.

The natural slope of the beach depends on the physical characteristics of the beach material (sediment) and its porosity, which enables significant infiltration and absorption of incoming waves. Sediment transport occurs near the contact line of the sea and coast, primarily in the narrow zone of breaking waves and swash, which also depends on the slope of the beach itself [6]. Composite beaches comprising sand and gravel differ significantly in morphodynamic characteristics from beaches with pure gravel or a mixture of gravel and sand separated in the cross-section of beach [7]. Due to the complexity of the transport mechanism, the methodology established on the principles of fundamental physics, which facilitates the universal quantification of sediment transport, has not been presented so far [8].

According to the Udden-Wentworth classification, gravel (pebble) material implies the predominance of gravel sediment in the grain diameter range of 2-64 $\mathrm{mm}$. The slope of gravel beaches is usually higher than that of sandy beaches, with slopes often exceeding $10^{\circ}$ [9]. Jennings and Shulmeister [10] concluded that gravel beaches have steeper slopes, noting that the slope can vary significantly depending on the fraction of finer material in the sand domain. Buscombe and Masselink [9] focused on the importance of the infiltration-exfiltration process of filtration in the body of the gravel beach on the overall morphodynamics.

Optical and acoustic measurements using new-generation devices enable quality monitoring of the morphodynamic characteristics of gravel beaches under dynamic environmental conditions. Therefore, in recent times, apart from long-term morphological changes in beach profiles $[11,12,13,14]$, short-term changes are increasingly being observed $[15,16,17]$, and appropriate models of the morphodynamics of gravel beaches are being established.

Empirical models of the equilibrium cross-section profile of the wet part of a sandy or gravel beach, described in $[18,19,20]$ link the change in depths (bottom level) as a function of the shoreline distance and rely on the grain diameter of the beach material. A comparison of the results obtained using such empirical formulae and gravel beach profiles measured in nature indicates the reliability of their application only under homogeneous environmental conditions $[21,22,23,24]$.

In the recently published results of a study by Bujan et al. [25] based on 2144 pairs of beach slope data $(\beta$ in degrees) and beach material grain diameter (the median grain size diameter $D_{50}$ ranged from $0.063 \mathrm{~mm}$ to 4096 $\mathrm{mm}$ ), empirical formulae in an exponential form with two parameters $\left(\tan \beta=a D_{50}{ }^{b}\right)$ and three parameters (form 1 $\rightarrow \beta=a D_{50}{ }^{b}+c$; form $\left.2 \rightarrow \beta=a\left(D_{50}-0.125\right)^{b}+c\right)$ are systematized. The suggested values for the coefficients of the empirical formulae are $a=-0.178, b=-0.187$, and $c=0.294$ (form 1), and $a=-0.154, b=-0.145$, and $c=$ 0.268 (form 2). Such expressions can also be used to determine the maximum allowed slope of the beach when constructing artificial gravel beaches or nourishing them.

To analyze the response of the cross-section profiles of mixed gravel-sand beaches to the wave impact, Karunarathna et al. [26] and Horrillo-Caraballo and Reeve [27] used canonical correlation analysis (CCA). CCA is a multivariate linear statistical analysis that can be applied to detect a pattern of behavior in the development of beach profiles and incident wave conditions. Using CCA, a regression matrix is derived that relates the beach profile to the characteristics of the wave spectra. Therefore, it is necessary to have two time series of data (cross-section

Lončar, G, Kalinić, F, Carević, D, Bujak, D 
profiles and corresponding spectral characteristics of the waves) at the same time resolution. A detailed description of the CCA methodology is provided in [28].

A relatively small number of numerical models have been developed to analyze the morphodynamics of beaches with mixed or predominantly gravel material [29,30,31], partly because of the relatively limited database obtained by measurements in nature and in laboratories. Pedrozo-Acuña et al. $[6,30]$ presented the results of a numerical empirical research on sediment transport in the swash zone for steep gravel beaches using a nonlinear Boussinesq model for the wave model. Ruiz de Alegria-Arzaburu and Masselink [5] estimated the 3D morphodynamics for a gravel beach on the southwest coast of the UK exposed to the impact of wind waves and swells. During and intensive two-year in situ monitoring (April 2007-April 2009), 27 storm situations were registered. The Mike 21/sw (www.dhigroup.com) spectral model based on the finite volume method with an unstructured calculation network was used to analyze wave deformations and calculate the wave field in the deep, transitional, and shallow-water areas. Longshore sediment transport was initially calculated using the measured morphological changes in beach profiles, and subsequently compared with the results of the application of empirical formulae defined in the papers $[32,33,34]$.

In [35], the results of in situ measurements and numerical modeling of wave deformations (Mike 21/sw model, http://www.dhigroup.com) and morphological changes (XBeach-G model, http://oss.deltares.nl) along a crosssectional profile of a natural gravel beach over a period of one year (Kvarner Channel in the northern part of the Adriatic basin, Croatia) are presented. The model results indicated the most intense erosion in the swash zone and sedimentation of the material in the greater depth zone. The measured and simulated morphodynamics indicated a natural tendency towards a dynamically stable profile. A comparison of the results of the studies conducted with those of others at nearby locations and under the same meteorological conditions exhibited quantitative similarity in the extent of material erosion along the cross-section of the beach.

In this study, a numerical analysis of the morphodynamics of Ploče Beach was conducted (Figure 1) for the period from 9.2.2020 to 12.2.2020 after the beach was nourished on 1.2.2020 to increase the beach area. Detailed terrain surveys in the form of point clouds $\left(\approx 4 \mathrm{E}^{7}\right.$ points) were conducted on 8.2.2020 and 12.2.2020 In the implemented model routines, the main force for the movement of gravel is gravitational wind waves, while the influence of sea currents induced by tidal forces, gradient currents, and drift currents has been excluded.

In Chapter 2, basic explanations of the measurements provided and the implementation of numerical and empirical models of wave deformation and morphodynamics are provided. In Chapter 3, the results of the implementation of model simulations and application of empirical formulae are presented, while the concluding chapter provides an overview of the research conducted and the results obtained.
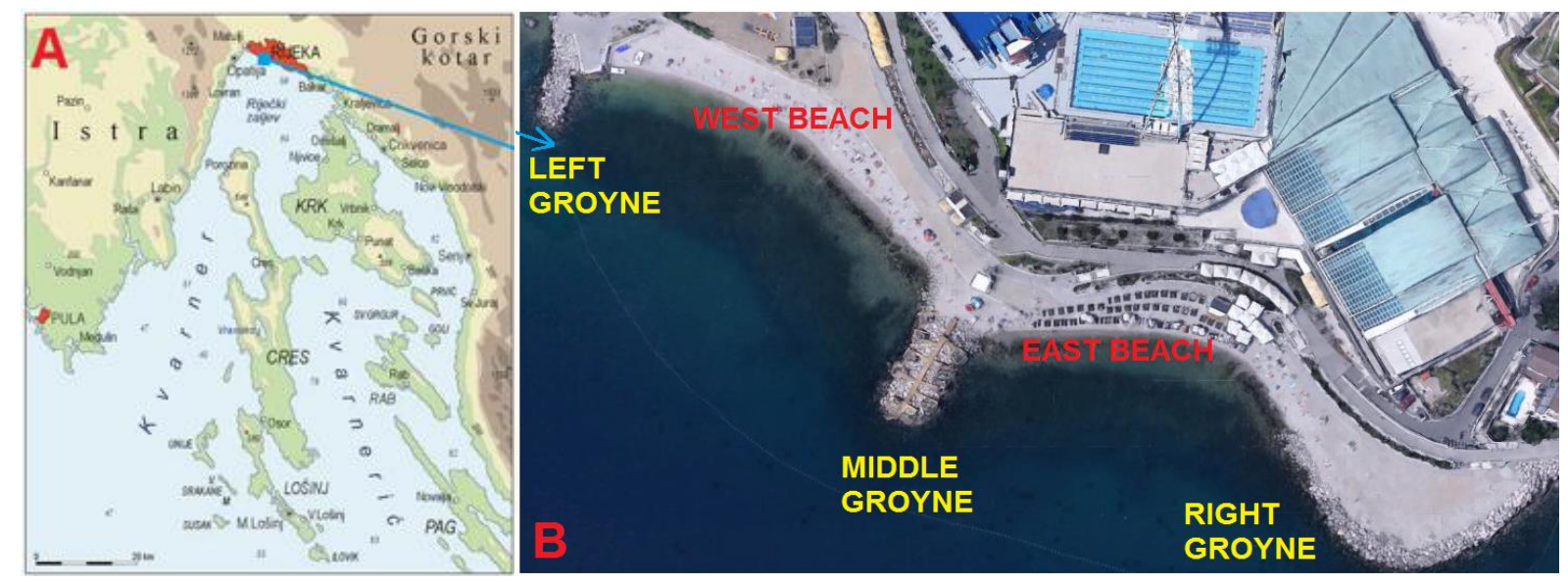

Figure 1 Map of the wider area (Kvarner) indicating the location of the conducted research and view of the Ploče beach (B) 


\section{MATERIALS AND METHODS}

\subsection{Terrain and wave measurements}

The Datawell waverider was used (Figure 2) to measure the waves at position V1 in the immediate vicinity of the Ploče beach itself ( $\varphi=45^{\circ} 19.588^{\prime} \mathrm{N} ; \lambda=14^{\circ} 23.738^{\prime} \mathrm{E}$, WGS 84 , free movement within the radius of the position). The wave motion sensor consists of a buoy (type MKIII) with a built-in GPS receiver and digital data logger. Data was transmitted from the measuring buoy to the recorder using radio and GSM communication. The waverider sensor recorded data containing standard wave statistics for periods of $30 \mathrm{~min}$ (Figure 3 ). In the observed situation, the measured maximum of the significant wave height was $H_{S}=1.16 \mathrm{~m}(10.2 .2020 .16: 30)$, with the associated maximum wave height $H_{M A X}=2.54 \mathrm{~m}$, peak spectral period $T_{P}=4.35 \mathrm{~s}$, in the incident wave direction Dir $=195.5^{0}$.

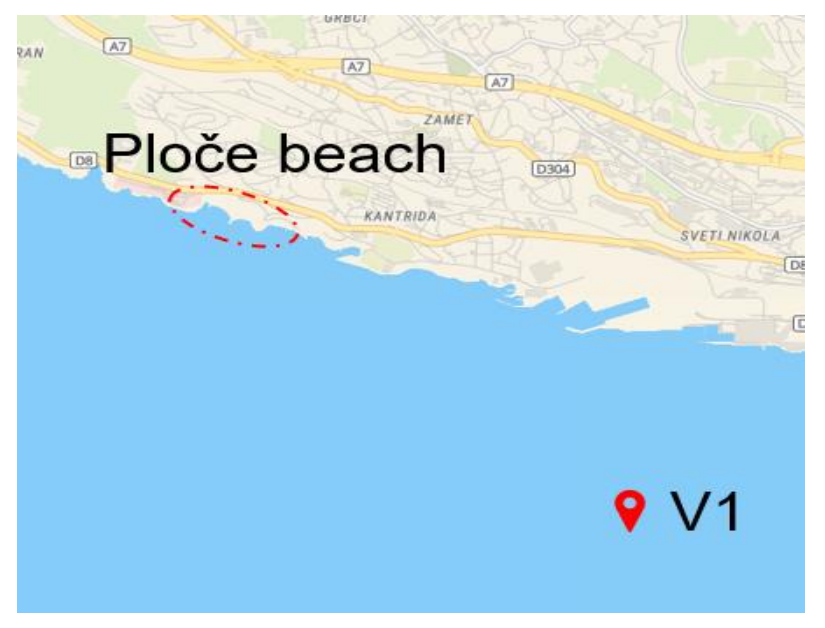

Figure 2 Map of the wider area indicating the locations of the conducted research (Ploče beach) and wave buoy (V1)

Point clouds for the research location were taken on 8.02.2020. and 12.02.2020. (Figure 4). Every point cloud contained approximately $4 \mathrm{E}^{7}$ points. Figure 4 shows the sampling positions of the beach material (8.2.2020) and control cross-section profiles (L1-L10) used in further analyzing the longshore transport of the beach material. The starting points of the profile were at a depth of $5 \mathrm{~m}$. The results of the laboratory grain size distribution testing of the beach material showed that the median grain size diameter obtained from the test sample was $d_{50}=16 \mathrm{~mm}$.
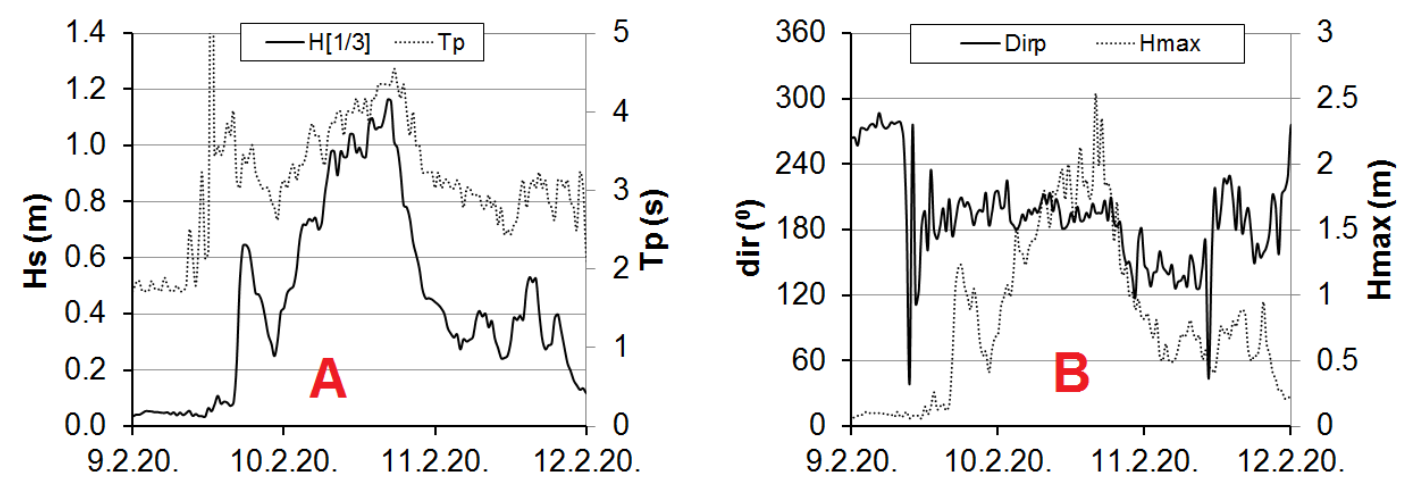

Figure 3 Time series of $H_{S}(\mathrm{~A}), T_{P}(\mathrm{~A}), \operatorname{Dir}(\mathrm{B})$ and $H_{M A X}(\mathrm{~B})$ at half-hour resolution for the period of analysis from 9.12.2020. - 12.12.2020. (registered at the wave motion sensor V1) 

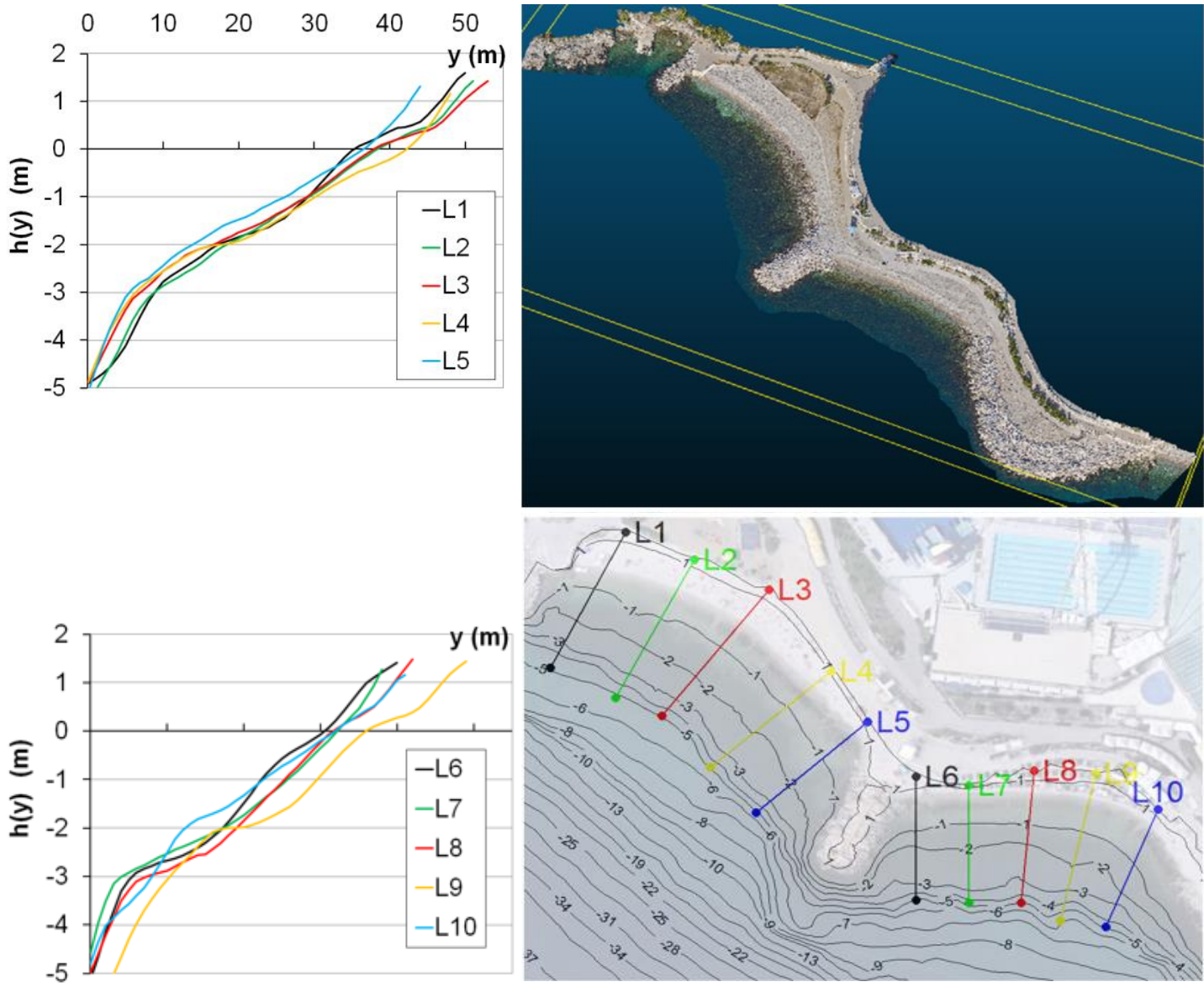

Figure 4 Survey terrain image made with Structure-from-Motion (SfM) photogrammetry (4E7 - 08.02.2020), sampling positions of the grain size distribution of the beach material G1 and G2, and control crosssection profiles L1-L10 with associated bottom slopes

\subsection{Numerical wave deformation and sediment transport model}

A wave deformation model was established for the spatial domain, as shown in Figure 5. The spatial and time distributions of significant wave heights $H_{S}$, peak periods $T_{P}$, incident wave directions, and wave-breaking index during the period 8.2.2020 to 12.2.2020 were analyzed using this model. The distance between the numerical nodes, located at the center of gravity of the surface of each finite volume, was variable and extended from $5 \mathrm{~m}$ in the deep-water area to $0.5 \mathrm{~m}$ in the coastline zone. Using numerical simulations, half-hourly averaged fields of significant wave height $H_{S}$, peak period $T_{P}$, incident wave direction, and wave breaking zone were obtained. For the sediment transport model, it is necessary to know the wave-generated unsteady flow field. Therefore, a $2 \mathrm{D}$ vertical-averaged Mike $21 \mathrm{fm}$ model (www.dhigroup.com) was established in which the radiation stress field from the results of the wave deformation model was used for forcing sediment transport. The model used the same model domain and computational grid as the wave deformation model (Figure 5).

\section{Initial conditions}

The initial simulation conditions were defined by the zero-wave spectrum, that is, by the absence of initial wave motion over the entire modeled area. The dynamics of the calm sea level were considered based on the registered data from the Bakar mareographic station (Figure 5).

\section{Boundary conditions}

At the open boundaries of the wave deformation model (Figure 5), the measured time series of significant wave height $H_{S}$, peak periods $T_{P}$, and associated incident wave direction were applied, according to registration at 
waverider station $\mathrm{V} 1$ with half-hour data resolution (Figure 3). The wave steepness in the analyzed situation was $\mathrm{s}$ $=24,9$ and for the purposes of the model the wave breaking coefficient was applied according to [36]

$$
\gamma_{B}=0.5+0.4^{*} \tanh \left(33^{*} s\right)=0.85
$$

\section{Numerical wave deformation model}

The Mike 21sw spectral numerical model (www.dhigroup.com) was used to numerically analyze the wave deformations. A full spectral formulation was used with the directional wave spectrum as the dependent variable. For the spectral discretization of the frequency domain, a logarithmic scale from the minimum frequency of $0.1 \mathrm{~Hz}$ (10 s wave period) to the maximum frequency of $1.75 \mathrm{~Hz}(0.57 \mathrm{~s}$ wave period) was used, over 30 discrete steps. Model implementation included inter-wave nonlinear interactions, refraction, diffraction, and shoaling, as well as dissipative processes caused by friction with the bottom and wave-breaking upon reaching shallow depths.

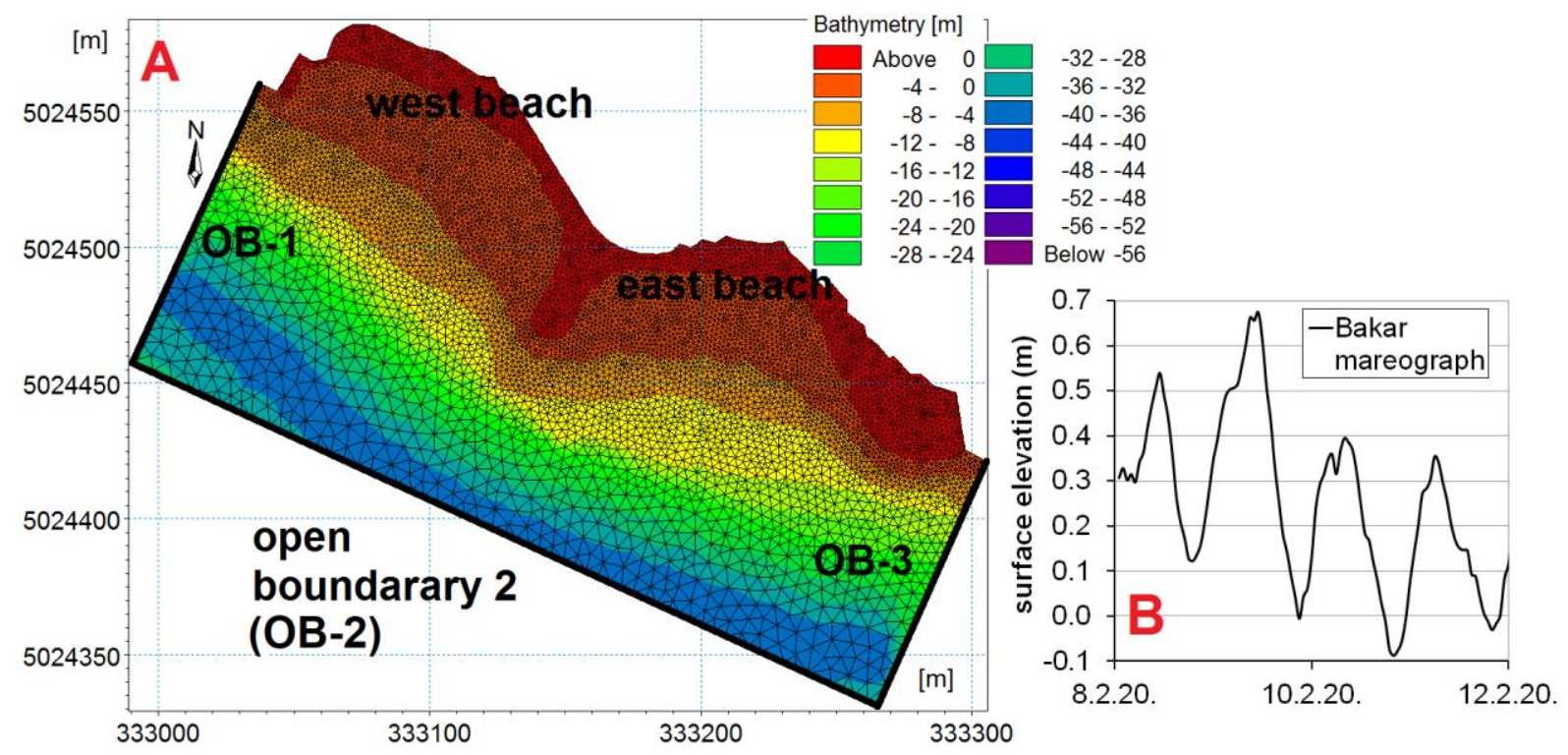

Figure 5 Spatial domain of the numerical wave deformation model and its discretization with an unstructured finite volume network on a bathymetric background $(A)$ and a mareographic record of sea level dynamics during the simulation (B)

To calculate the sediment transport, information about the time-averaged mean flow field is essential. The mean flow was calculated through the superposition of wave motion, flow due to the gradient of the water surface, and flow in the boundary layer that develops through the combined action of currents and waves. The timeaveraged mean flow field was calculated from the mean eddy viscosity coefficient and radiation stress field.

The general wave parameters $H_{S}, T_{P}$, and incident wave direction, calculated using the wave deformation model, were used to describe the wave motion. In the case of wave breaking, the energy of the orbital motion is converted to surface turbulence, which is transferred into deeper layers. The surface layer turbulence production was calculated using the wave height, wave period, and depth parameters [37,38]. The surface radiation stress due to wave breaking depends on the size of the surface roller formed, the surface of which is calculated according to the theory presented in [39].

The development of the boundary layer through the combined action of currents and waves was considered by the approach outlined in the paper [40]. The equilibrium force equation includes the contributions of the orbital wave motion, forces generated by the breaking of waves (radiation stress gradient), and slope of the water surface. In the model used, it was solved by the classic 4th order Runge-Kutta method (RK4).

Turbulence

Turbulence production was considered through three partial contributions: the wave boundary layer, energy dissipation through surface wave breaking, and mean flow. It was quantified using the eddy viscosity coefficient: 


$$
U_{T}=U_{T-B L}+U_{T-C}+U_{T-W B}
$$

The partial contributions are given by the corresponding member of eddy viscosity. The contribution of the wave

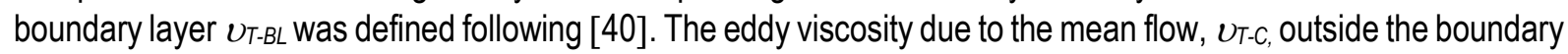
layer was calculated by applying the mixing length concept [41], while the eddy viscosity owing to wave breaking, $U_{T-W B}$, was calculated from the transport equation for turbulent kinetic energy [42].

The production of turbulent energy to wave breaking is equal to the dissipation of the wave energy.

$$
\text { Diss }=0.25 F_{B} H_{\max ^{3}} \rho g /(T h) \text { [36], }
$$

where $F_{B}$ is the fraction of broken waves

$$
F_{B}=1+H_{s}^{2} \ln F_{B} / 2 H_{\text {max }}^{2} \text {, }
$$

and $H_{\max }$ is the maximum wave height

$$
H_{\max }=\tanh \left(\gamma_{B} k h\right) / k
$$

The parameters $k, h$, and $\gamma_{B}$ represent the wave number, local depth, and wave breaking coefficient, respectively (applied value of $\gamma_{B}=0.85$ ).

\section{Mean flow}

The mean flow is generated by the shear stress field, which is expressed in the model using three partial components: time-averaged shear associated with the wave motion, shear stress due to wave breaking, and shear stress due to gradients in the water surface [43].

For the wave motion outside the boundary layer, the potential theory assumption was applied according to which the mean bottom shear stress was 0 (pure oscillatory motion). On the other hand, for progressive waves, the bottom shear stress has a finite value other than zero because of the non-uniformity of the wave boundary layer. Therefore, in the model, a small constant velocity was added to the orbital wave motion, and it was iteratively calculated through the condition of equality of the bottom shear stress from the turbulent boundary layer and the predefined value [44].

The relationship between the radiation stress gradient and time-averaged shear stress was defined according to the concept described in $[42,44]$, which recognized the importance of the vertical transfer of the horizontal component of momentum in the law of conservation of momentum balance. The time-averaged shear stress, calculated based on the energy dissipation in the wave breaking, was uniform throughout the entire water column.

The mean flow in the cross-section direction must balance the mass transport associated with the wave motion and discharge in the surface roller. In the longshore direction, the mean flow corresponds to the timeaveraged longshore current velocity. Therefore, in the model, the predefined mean flow was obtained by superposing a shear stress arising from a sloping water surface to the shear stress associated with the wave motion (radiation stress, surface roller). The shear stress owing to the sloping water surface was zero at the water surface and grew linearly towards the bottom.

\section{Sediment transport}

Sediment transport in the longshore direction is defined by the following deterministic expression [43]

$$
q B L=5[1+(\beta \pi / 6) /(\theta B-\theta B C)]-0.25(\theta B 1 / 2-0.7 \theta B C 1 / 2)[g(\rho s / \rho-1) d 503] 1 / 2,
$$

where $g$ represents gravity and $\theta_{B}$ is the non-dimensional shear stress at the bottom

$$
\theta B=\tau b /[(\rho s-\rho) g d 50] \text {. }
$$

The parameters $\rho_{\mathrm{s}}$ (sediment density, $2650 \mathrm{~kg} / \mathrm{m}^{3}$ ), $\rho$ (sea density, $1028 \mathrm{~kg} / \mathrm{m}^{3}$ ), and $\theta_{B C}$ (non-dimensional critical shear stress at the bottom) were calculated using the following expression:

$$
\theta_{\mathrm{BC}}=0.0495\left\{\left[-\cos \alpha \sin \beta+\left(\mu_{\mathrm{s}}^{2} \cos ^{2} \beta-\sin ^{2} \alpha \sin ^{2} \beta\right)^{1 / 2}\right] / \mu_{S}\right\},
$$

where $d_{50}, \alpha \llbracket \beta, \mu_{S}=\tan \phi$, and $\phi$ denote the median grain size diameter of beach material sample, angle between current direction and bottom slope, bottom slope angle, static coefficient of friction, and angle of internal friction 
(angle of repose), respectively. Sediment transport in the longshore direction was calculated by the following expression:

$$
q_{B T}=q_{B L} \tan \beta /\left(1.6 \theta_{B}^{1 / 2}\right) .
$$

For sediment gradation $\sigma_{g}=\left(d_{84} / d_{16}\right)^{1 / 2}$ value of 1.1 was adopted [45].

The solution of hydrodynamics with the associated sediment transport is initially calculated within the calculation of morphodynamics, for each calculation step, which determined the rate of change of the bottom elevation. The bathymetric data file was updated based on the calculated values of the rate of change of bottom elevation, and with the changed bathymetry, a further calculation step was performed for hydrodynamics and sediment transport.

Figure 6 shows the spatial distribution of the initial thickness of the gravel layer with an approximately homogeneous beach material, $d_{50}=16 \mathrm{~mm}$. The rest of the beach and underwater contain stabilized material that is considered immobile in the model, while the groins are constructed with riprap material $\left(d_{50}>>16 \mathrm{~mm}\right)$. Therefore, the above conditions were used as the initial conditions for the sediment transport model.

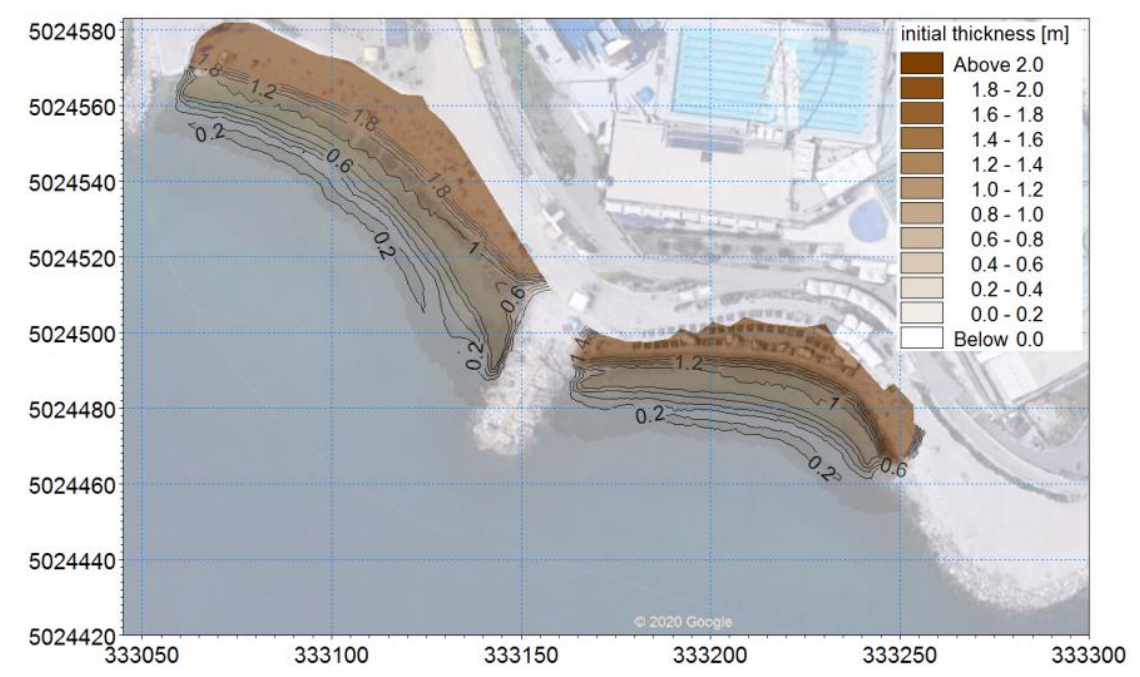

Figure 6 Spatial distribution of the movable sediment layer thickness of granulation $d_{50}=16 \mathrm{~mm}$ (initial conditions for the transport model)

\subsection{Empirical model (formulae) of longshore sediment transport}

The empirical formulae given in [46] (10), [32] (11), and [34] (12) were used to quantify the longshore component of sediment transport:

$$
\begin{aligned}
& Q_{b}=0.0012 \frac{H_{S B} \sqrt{\cos \theta}}{d_{50}}\left[\frac{H_{S B} \sqrt{\cos \theta}}{d_{50}}-11\right] \sin \theta_{B} g d_{50}^{2} T_{P B}, \\
& Q_{b}=k \frac{(1+e) \rho H_{S B}^{2} C_{g} \sin 2 \theta_{B}}{16\left(\rho_{S}-\rho\right)}, \\
& Q_{b}=1.34 \frac{(1+e) H_{S B}^{2.49} T_{Z}^{1.29} \tan \beta^{0.88} d_{50}^{-0.62} \sin 2 \theta^{1.81}}{\left(\rho_{S}-\rho\right)} .
\end{aligned}
$$

Where the following represent: $Q_{b}$ the intensity of longshore sediment transport $\left(\mathrm{m}^{3} / \mathrm{s}\right), k$ empirical coefficient (adopted value 0.057 [5]), e beach material porosity (adopted value 0.4), $\rho_{s}$ sediment density (adopted value 2650 $\mathrm{kg} / \mathrm{m}^{3}$ ), $\rho$ sea density (adopted value $1028 \mathrm{~kg} / \mathrm{m}^{3}$ ), $C_{g}$ wave group velocity, $H_{S B}$ significant wave height at the

Lončar, G, Kalinić, F, Carević, D, Bujak, D 
breaker line, $T_{Z B}$ mean wave period at the breaker line, $T_{P B}$ peak wave period the breaker line, $\beta$ bottom slope angle (beach face slope), $\theta_{B}$ angle of wave attack at the coast. The main problem in applying the above formulae lies in determining the corresponding values of $H_{S B}, \theta_{B}$, and $T_{P B}$. In this study, these values were obtained by processing the results of a numerical model of wave deformations.

\section{RESULTS OF THE NUMERICAL MODEL AND EMPIRICAL FORMULAE}

Figure 7 shows the field of significant wave height $H_{S}$ at 10.2.2020. 16:30, when the maximum significant wave height $H_{s}$ during the simulation period of 08.02.-12.2.2020 was registered at the waverider station V1. Figures 8 and 9 depict the field of the wave breaking index and currents generated by the waves for the same period. Figure 10 shows the field of the bottom elevation change at the end of the simulation period (12.2.2020.). Figure 10 also shows the bottom elevation change over the entire simulation period in cross-sections L1, L4, L8, and L10.

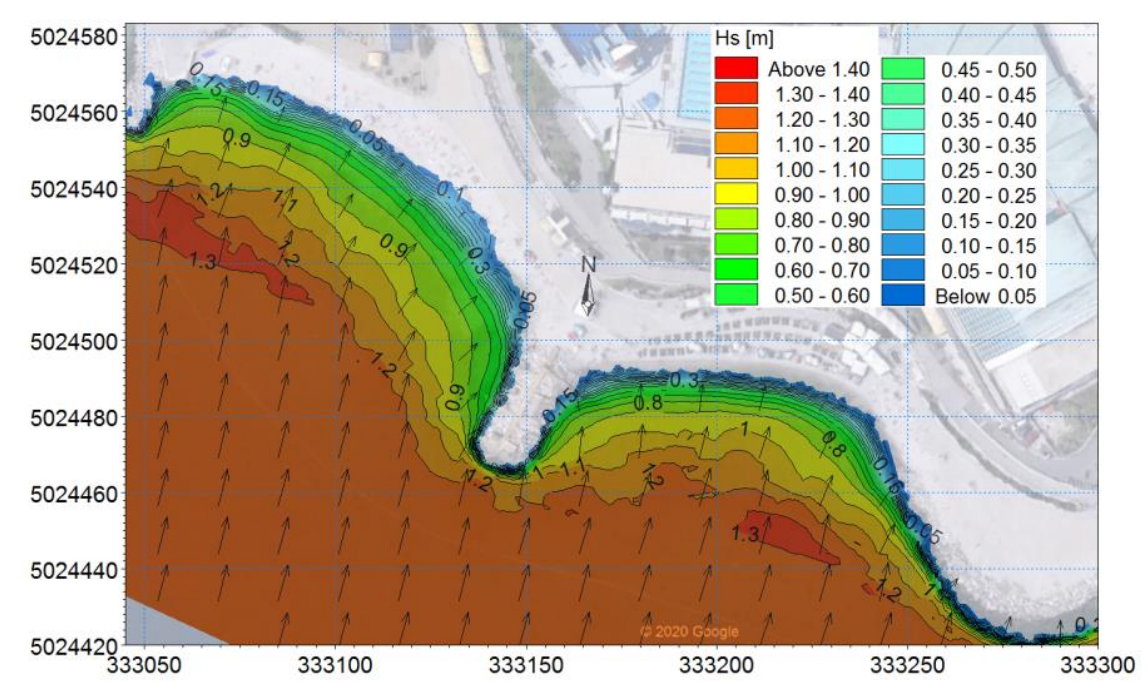

Figure 7 Significant wave height field at the maximum significant wave height period (2/10/2020 16:30 PM)

Figure 7 shows that the significant wave heights $H_{s}$ increase locally owing to the shoaling effect (relative to the position of the open boundary), reaching maximum values of $H_{s}=1.32 \mathrm{~m}$. During the period of maximum waves (10.2.2020. 16:30), the angle of incidence in the deep-water area was dir $=195^{\circ}$, so the waves, reached to the coastline from the perpendicular direction in the central parts of the "west" and "east" beach after the additional refraction impact. 


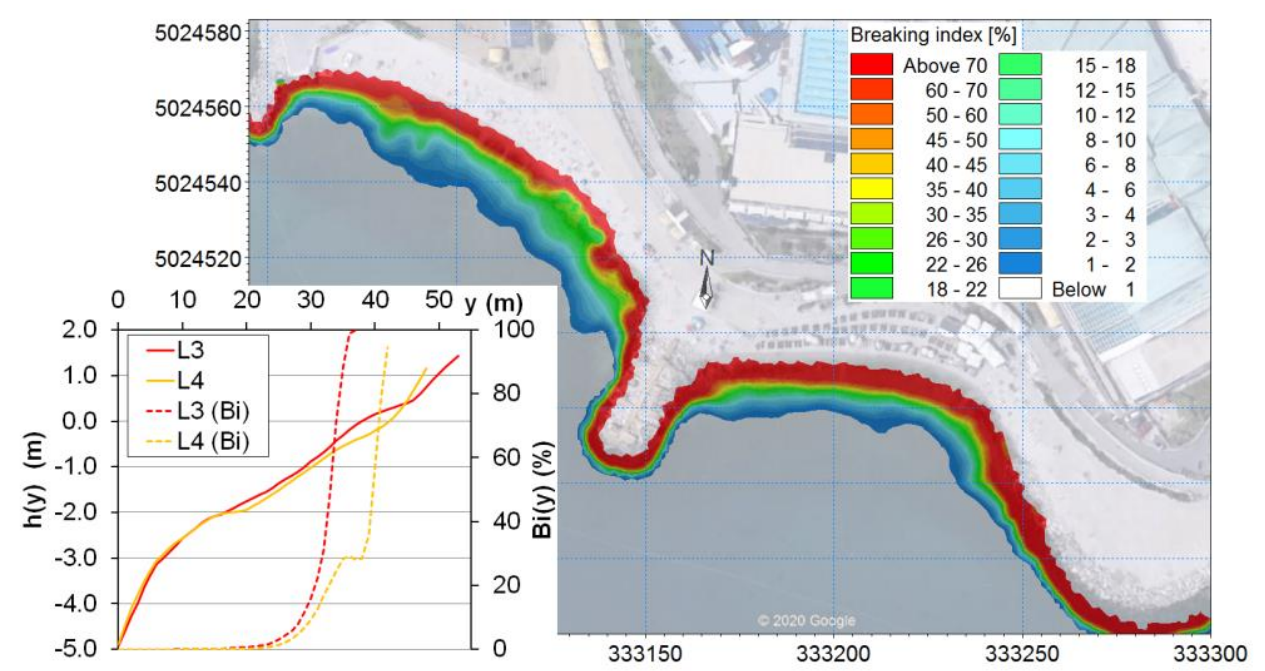

Figure 8 Field of the wave breaking index during the period of maximum significant wave $(10.2 .2020$.

16:30)

Figure 8 shows that up to $5 \%$ of waves break at depths exceeding $1.5 \mathrm{~m}-2.0 \mathrm{~m}$ ( $\approx 10-15 \mathrm{~m}$ from the shore), after the percentage of broken waves occurs increases suddenly. In areas with milder changes in the bottom elevation, the wave-breaking zone is wider.

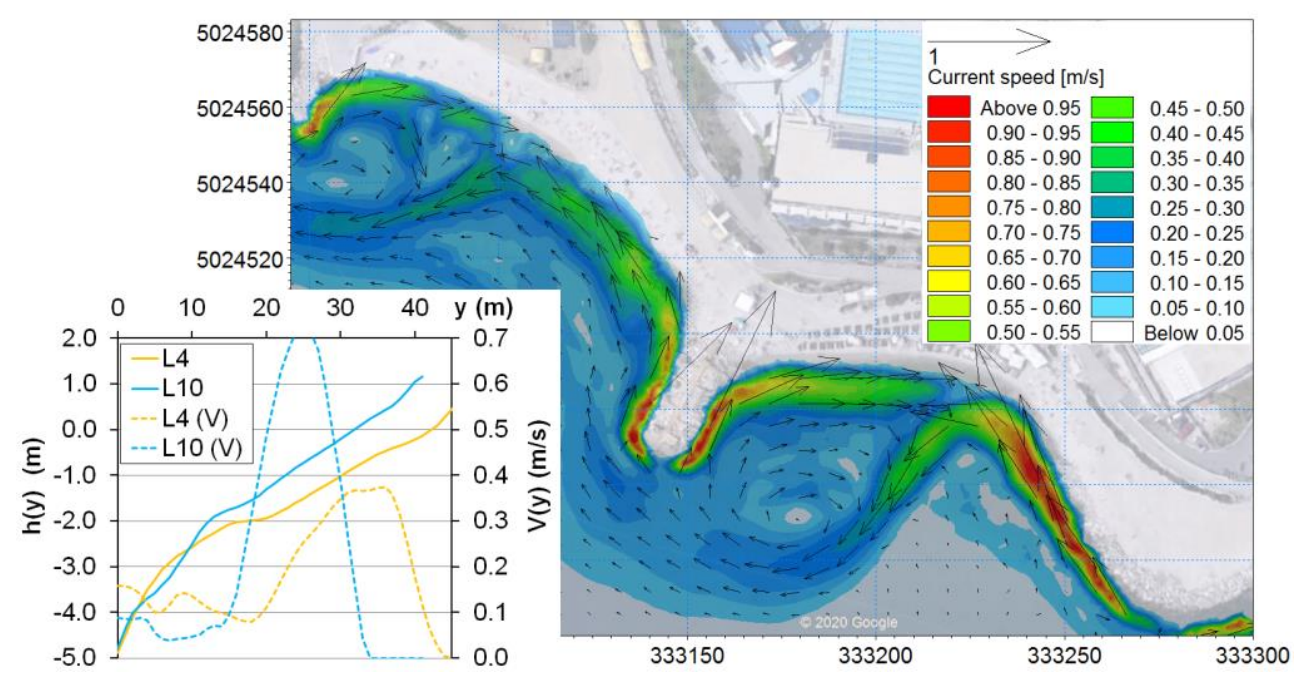

Figure 9 Current field generated by the radiation stress gradient in the period of the maximum significant wave height (10.2.2020. 16:30)

The results in Fig. 9 indicate large gradients in the field of the wave-generated current. The highest velocities occur along the groins, where the sediment is significantly larger than the median grain size $d_{50}=16 \mathrm{~mm}$ of the beach material. Therefore, the morphodynamic activity in these zones was less prominent. The strongest currents in the zone with beach material median grain size $d_{50}=16 \mathrm{~mm}$ occurred in profile L10, and more significant morphological changes are expected in this profile (Figure 10). 


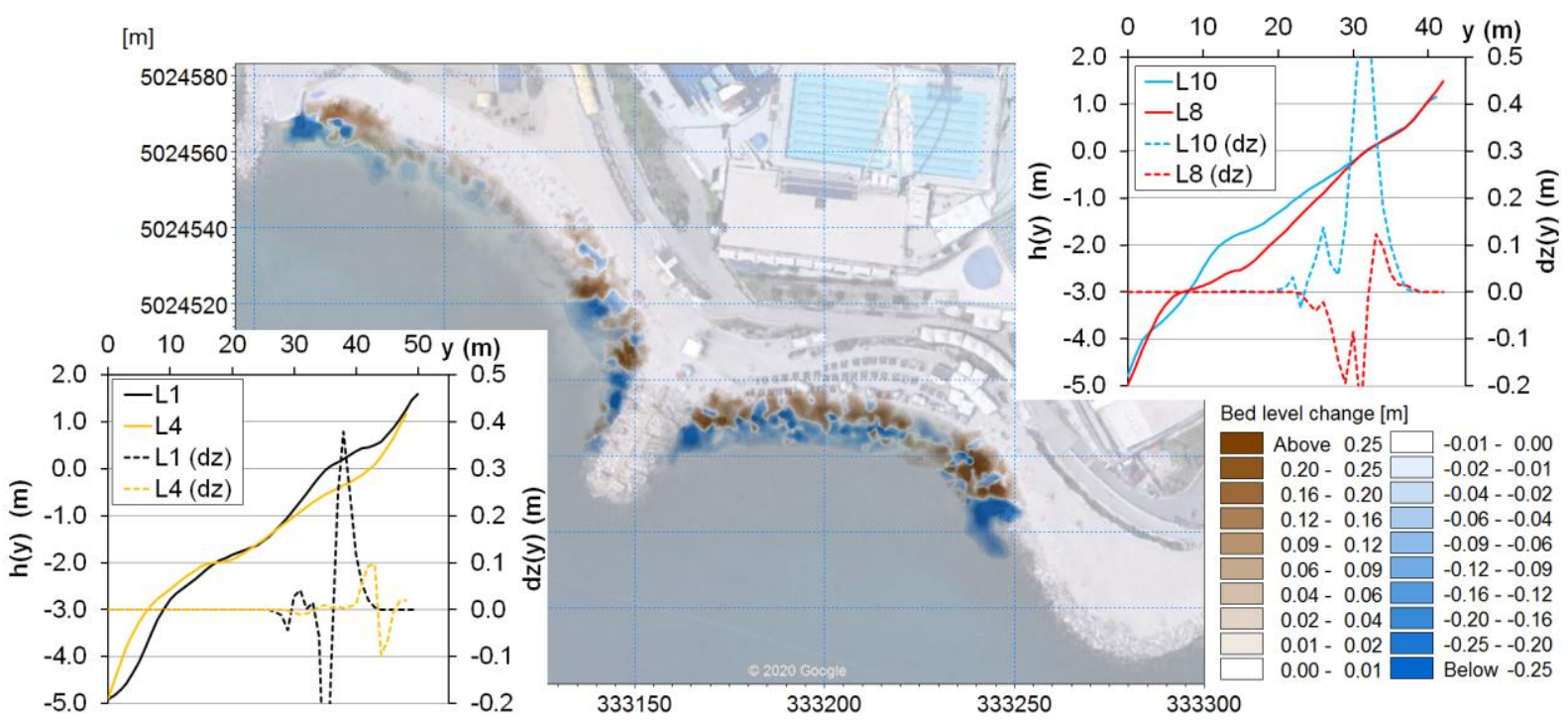

Figure 10 Field of the change in the bottom elevation at the end of the simulation period (12.2.2020) and change in the bottom elevation in profiles L1, L4, L8 and L10

The results shown in Figure 10 indicate the significant non-uniformity of the erosion and accumulation fields of the sediment, primarily to the presence of both the longshore and cross-shore sediment transport components. The most significant erosion and accumulation of beach material occurs at the right edge of the "eastern" beach. At beach elevations above the hydrographic zero, material accumulation prevails. In contrast, erosion prevails in the submarine part of the beach (below hydrographic zero). The lowest erosion can be observed in profiles $L 2$ and L3 as the wave breaking zone is wider; hence the dissipation of wave energy is widespread due to milder changes in the bottom elevation. In addition, the lowest wave-generated current speed can be observed in profiles $L 2$ and L3. The quantification of the change in volume by segments between the profiles and summed up for the whole beach is given below compared with the results of the calculation based on empirical formulae.

Figure 11 shows the intensities of the sediment transport $Q_{b}$ in profiles L1-L10 during the period 9.2.12.2.2020, calculated on the basis of empirical formulae (10), (11), and (12). The positive values indicate the sediment transport in the direction $\mathrm{E} \rightarrow \mathrm{W}$, while negative values indicate the transport direction $\mathrm{W} \rightarrow \mathrm{E}$. The results show that maximum transport occurs in profiles L5 ("west" beach) and L8 ("east" beach). The values obtained using formulae (12)[34] are four times smaller than the results obtained with the remaining two expressions. Because only in (12)[34] parameters of bottom slope $\beta$ and median grain size diameter $d_{50}$ occur, and that (12) is derived from recent in-situ studies, for further calculations, the results obtained using (12) are adopted. 

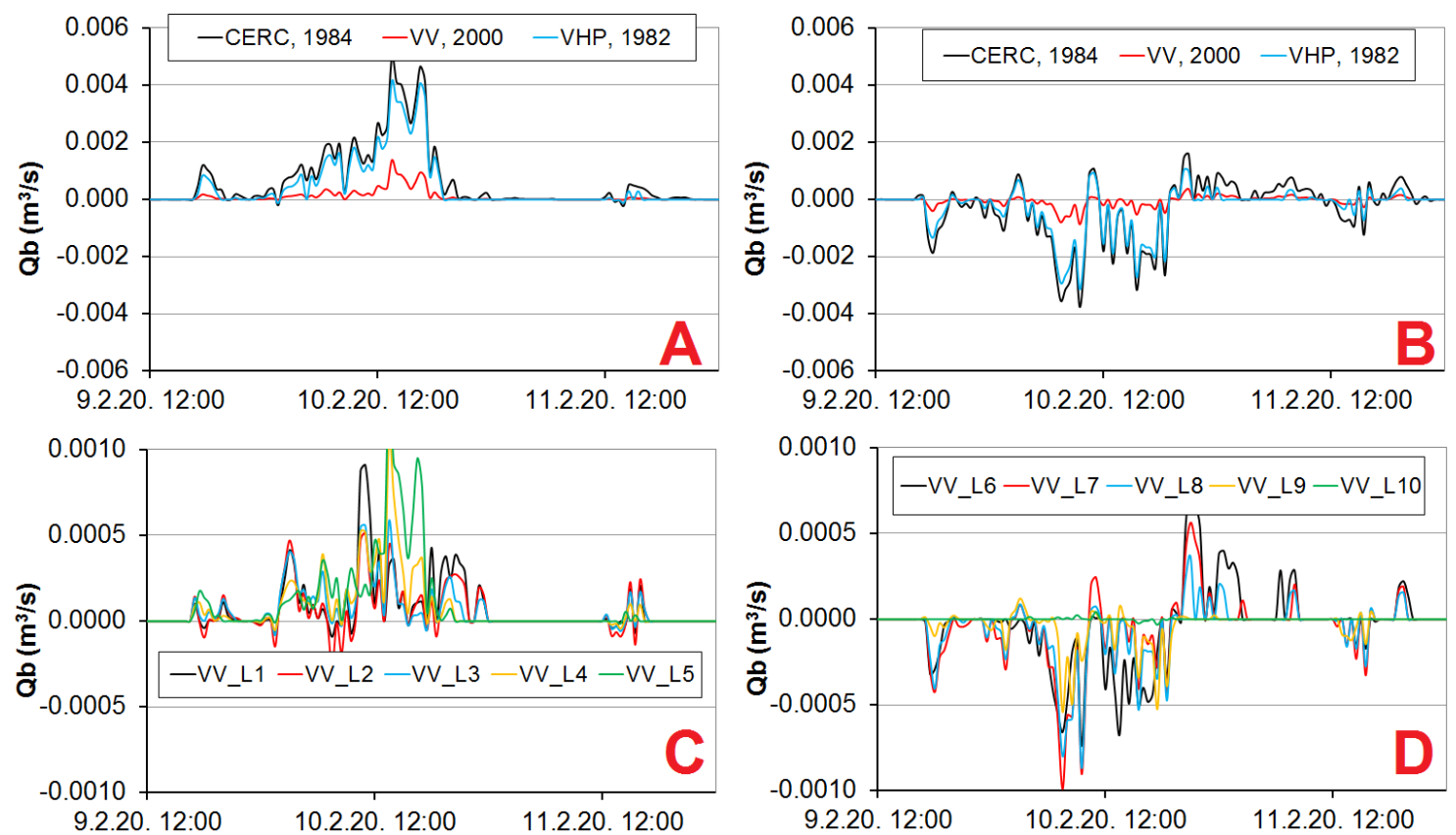

Figure 11 Intensity of $Q_{b}$ transport in profiles L5 (A) and L8 (B) based on the empirical formulae (10), (11) and (12), and $Q_{b}$ in profiles L1 - L5 (C) and L6-L10 (D) based on the empirical formulae (12)

It is also possible to determine the parts of the beach where erosion and accumulation occur from the results of longshore sediment transport through profiles 1-10. The difference in the intensity of the total longshore transport between the two adjacent profiles causes erosion (greater transport through the output profile than input) or accumulation (greater transport through the input profile than transport through the output profile). Figure 12 shows the total erosion/accumulation volumes along the beach between the used profiles L1-L10 for the analyzed period of 9.2.2020.-12.2.2020. The results obtained using a numerical model of sediment transport are also presented for comparison. The erosion/accumulation volume was calculated from the results of the numerical model for the sections of the beach between the left groin and profile L1 (LG-1), profile L5 and middle groin (5-MG), middle groin and profile L6 (MG-6), and L10 profile and right groin (10-RG).

Figure 12 shows that the eroded/accumulated volumes calculated using the empirical formula (12) exceed the values obtained by the numerical sediment transport model. The sections where sediment erosion or accumulation occur are identical except for a section between profiles $L 1$ and $L 2$, where empirical formulae result in erosion, while the numerical results indicate accumulation. According to formula (12), erosion occurred in parts of the "west" beach between $L 1$ and $L 2\left(Q_{b-L 1}>Q_{b-L 2}\right)$, while accumulation occurred in the other parts of the "west" beach between $L 2$ and $L 5\left(Q_{b-L 5}>Q_{b-L 4}>Q_{b-L 3}>Q_{b-L 2}\right)$. For the "west" beach, a total volume change of $+6.1 \mathrm{~m}^{3}$ (accumulation) was obtained. Furthermore, in the "east" beach, the accumulation also exceeded erosion, producing a total volume change of $8.2 \mathrm{~m}^{3}$. It should be noted that the empirical expression (12) only covers the longshore transport component and that the term itself is derived from the results of in situ studies for relatively long coastal lines with minimal changes in the incident wave direction. The results of the numerical model indicate the trend of material accumulation in sections L1 - L5 and L8 - L10. Erosion occurs in sections LG - L1, L5 - MG, MG - L8, and $L 10-R G$. Therefore, one part of the eroded material from the peripheral parts of the beach (near groins) (LG - L1, L5 - MG, MG-L6, L10 - RG) is carried by longshore and cross-shore transport and accumulates at the parts of the beach that are higher than the hydrographic zero. The other part of the eroded material is carried to the central parts of the beaches, where it also accumulates. Total volume change of $+6.6 \mathrm{~m}^{3}$ (accumulation) and -7.8 $\mathrm{m}^{3}$ (erosion) were obtained for the "west" beach and "east" beach, respectively. Furthermore, using the results of the numerical model, it was estimated that the total accumulated sediment volume at the beach area above the hydrographic zero, which was displaced by erosion from the underwater part (below hydrographic zero), was approximately $+46 \mathrm{~m}^{3}$. These results are desirable from the perspective of beach sustainability and reduction of beach nourishment needs. 
Point cloud analysis for surveys made on 8.2.2020. and 12.2.2020. showed that the total change in the volume of beach material above sea level (hydrographic zero) was $+38 \mathrm{~m}^{3}$ (accumulation), which agrees with the results of the numerical model.
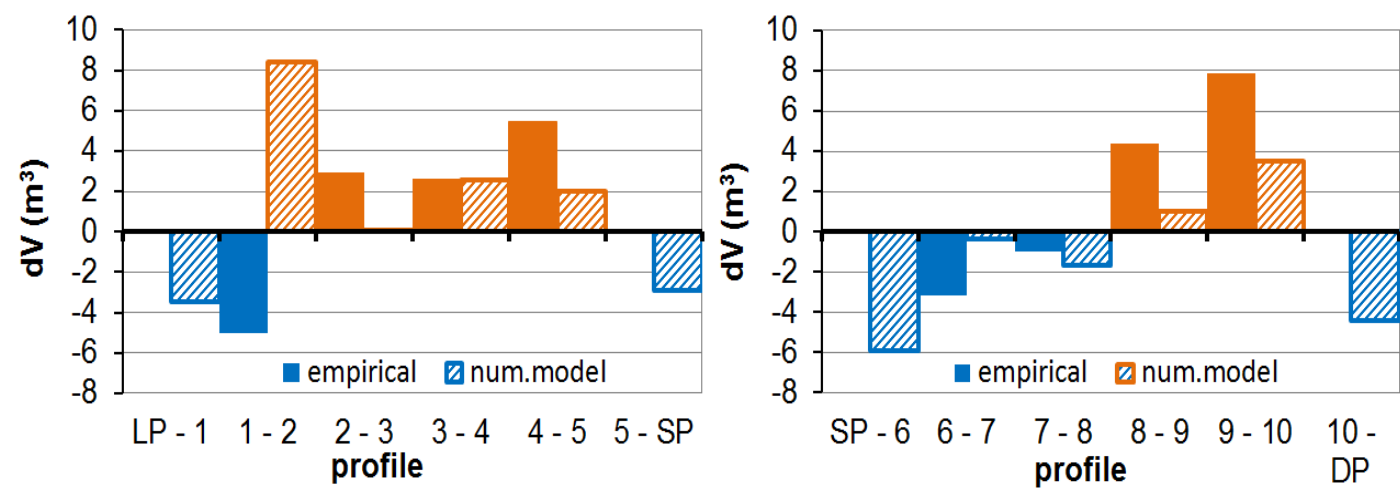

Figure 12 Total erosion/accumulation volumes along the beach between profiles $\mathrm{L} 1$ - $\mathrm{L} 10$ calculated
using the empirical formulae (12) and numerical sediment transport model

\section{CONCLUSION}

This study analyzed the morphodynamics of the artificial gravel beach Ploče in Rijeka for a situation where gravitational wind waves were incident from the SSW direction. Geodetic surveys of the beach were conducted at the beginning and end of the observed period using drones and SfM photogrammetry. Point clouds obtained from geodetic surveys were used to verify the model of morphodynamic changes on the surveyed beach.

For the purpose of numerical modeling, two models were established. The first model was a numerical wave deformation model, and its result, in the form of a field of radiation stress, was used to force the second numerical model of sediment transport. Furthermore, calculations of the longshore transport of the material using three empirical formulae were performed.

The results of the numerical model indicate the most significant erosion at the edges of the (along the groins), where the field of the wave-generated current is most pronounced. One part of the eroded sediment accumulated at the beach parts whose elevations were above the hydrographic because of the effects of cross-shore and longshore transport. The other part was carried to the central part of the beach where material accumulation also occurs.

The application of empirical formulae (12) can only provide a preliminary estimation of the intensity of the longshore component of sediment transport.

The change in the volume of beach material above the hydrographic zero, measured by surveying, agreed with the volume of accumulated material calculated using the numerical model.

The results obtained demonstrated that the establishment of this approach enables us to quantitatively describe the complex and under-researched morphodynamics of artificial gravel beaches. For further verification of the model, analyses covering a longer period in which a wider range of wave heights and incident wave directions occur need to be performed.

\section{Funding}

This work has been fully supported by the "Research Cooperability" Program of the Croatian Science Foundation funded by the European Union from European Social Fund under the Operational Programme Efficient Human Resources 2014-2020. 


\section{References}

[1] Almeida, L. et al. 2013: Observations of the swash zone on a gravel beach during a storm using a laserscanner, Journal of Coastal Research, Special Issue (65), Proceedings 12th International Coastal Symposium ICS 2013, Plymouth, pp. 636-641. https://doi.org/10.2112/SI65-108.1

[2] López de San Roman-Blanco, B. et al. 2006: Large scale experiments on gravel and mixed beaches: Experimental procedure, data documentation and initial results, Coastal Engineering, 53 (4), pp. 349-362. https://doi.org/10.1016/i.coastaleng.2005.10.021

[3] Masselink, G.; Russell, P.; Blenkinsopp, C.; Turner, I. 2010: Swash zone sediment transport, step dynamics and morphological response on a gravel beach, Marine Geology, 274 (1-4), pp. 50-68. https://doi.org/10.1016/i.margeo.2010.03.005

[4] Ružić, I. 2014: Dinamika žala u području Kvarnera, Disertacija, Građevinski fakultet Sveučilište u Rijeci (in Croatian).

[5] Ruiz de Alegria-Arzaburu, A.; Masselink, G. 2010: Storm response and beach rotation on a gravel beach, Slapton Sands, U.K., Marine Geology, 278 (1-4), pp. 77-99. https://doi.org/10.1016/i.margeo.2010.09.004

[6] Pedrozo-Acuña, A.; Simmonds, D.J.; Chadwick, A.J.; Silva, R. 2007: A numerical-empirical approach for evaluating morphodynamic processes on gravel and mixed sand-gravel beaches, Marine Geology, 241 (14), pp. 1-18. https://doi.org/10.1016/..margeo.2007.02.013

[7] Pontee, N. I.; Pye, K.; Blott, S.J. 2004: Morphodynamic behaviour and sedimentary variation of mixed sand and gravel beaches, Suffolk, UK, Journal of Coastal Research, 20 (1), pp. 256-276. https://doi.org/10.2112/1551-5036(2004)20[256:MBASVO|2.0.CO;2

[8] Van Rijn, L.C. 1993: Principles of Sediment Transport in Rivers, Estuaries and Coastal Seas, Aqua Publications, The Netherlands, 1006, pp. 11-13.

[9] Buscombe, D.; Masselink, G. 2006: Concepts in gravel beach dynamics, Earth-Science Reviews, 79 (1-2), pp. 33-52. https://doi.org/10.1016/i.earscirev.2006.06.003

[10] Jennings, R.; Shulmeister, J. 2002: A field based classification scheme for gravel beaches, Marine Geology, 186 (3-4), pp. 211-228. https://doi.org/10.1016/S0025-3227(02)00314-6

[11] Austin, M. J.; Masselink, G. 2006: Observations of morphological change and sediment transport on a steep gravel beach, Marine Geology, 229 (1-2), pp. 59-77. https://doi.org/10.1016/j.margeo.2006.02.003

[12] Carter, R. W. G.; Orford, J. D. 1993: The morphodynamics of coarse clastic beaches and barriers: a short term and long-term perspective, Journal of Coastal Research, Special issue, 15, pp.158-179.

[13] McKay, P. J.; Terich, T. A. 1992: Gravel barrier morphology: Olympic National Park, Washington State, U.S.A., Journal of Coastal Research, 8 (4), pp. 813-829.

[14] Forbes, D. L. et al. 1995: Morphodynamic evolution, self-organisation and instability of coarse clastic barriers on paraglacial coasts, Marine Geology, 126 (1-4), pp. 63-85. https://doi.org/10.1016/0025-3227(95)00066-8

[15] Ojeda, E.; Guillen, J. 2008: Shoreline dynamics and beach rotation of artificial embayed beaches, Marine Geology, 253 (1-2), pp. 51-62. https://doi.org/10.1016/..margeo.2008.03.010

[16] Curtiss, G. M.; Osborne, P. D.; Horner-Devine, A. R. 2009: Seasonal patterns of coarse sediment transport on a mixed sand and gravel beach due to vessel wakes, wind waves, and tidal currents, Marine Geology, 259 (1-4), pp. 73-85. https://doi.org/10.1016/j.margeo.2008.12.009

[17] Poate, T. et al. 2013: High frequency in-situ field measurements of morphological response on a fine gravel beach during energetic wave conditions, Marine Geology, 342, pp. 1-13. https://doi.org/10.1016/i.margeo.2013.05.009

[18] USACE (2008): Coastal Engineering manual, Part III, EM 1110-2-1100.

[19] Dean, R. G. 1987: Coastal sediment processes, toward engineering solutions, In Coastal Sediments' 87, Specialty Conference on Advances in Understanding of Coastal Sediment Processes, ASCE, New Orleans, LA, 1, pp. 1-24.

[20] Van der Meer, J. W. 1987: Stability of breakwater armour layers - design formulae, Coastal Engineering, 11 (3), pp. 219-239. https://doi.org/10.1016/0378-3839(87)90013-5

[21] Bradbury, A. P. 2000: Predicting breaching of shingle barrier beaches-recent advances to aid beach management, In Proceedings of 35th Annual MAFF Conference of River and Coastal Engineers, 5, pp. 1-5. 
[22] Obhrai, C.; Powell, K.; Bradbury, A. 2008: A laboratory study of overtopping and breaching of shingle barrier beaches, In Proceedings of 31st International Conference on Coastal Engineering, McKee Smith, J. (Ed), pp. 1497-1508. https://doi.org/10.1142/9789814277426_0124

[23] Bradbury, A.; Cope, S.; Prouty, D. 2005: Predicting the response of shingle barrier beaches under extreme wave and water level conditions in Southern England, In Proceedings of the Fifth International Coastal Dynamics Conference, Barcelona, Spain, pp. 1-14. https://doi.org/10.1061/40855(214)94

[24] Cope, S. 2005: Predicting overwashing and breaching of coarse - clastic barrier beaches and spits application to Medmerry, West Sussex, Southern England, In Proceedings of the Fifth International Coastal Dynamics Conference, Barcelona, Spain, pp. 1-14. https://doi.org/10.1061/40855(214)14

[25] Bujan, N.; Cox, R.; Masselink, G. 2019: From fine sand to boulders: Examining the relationship between beach-face slope and sediment size, Marine Geology, 417, 106012. https://doi.org/10.1016/i.margeo.2019.106012

[26] Karunarathna, $\mathrm{H}$. et al. 2012: An analysis of the cross-shore beach morphodynamics of a sandy and a composite gravel beach, Marine Geology, 299-302, pp. 33-42. https://doi.org/10.1016/j.margeo.2011.12.011

[27] Horrillo-Caraballo, J. M.; Reeve, D. E. 2010: An investigation of the performance of a data-driven model on sand and shingle beaches, Marine Geology, 274 (1-4), pp. 120-134. https://doi.org/10.1016/.margeo.2010.03.010

[28] Różyński, G. 2003: Data-driven modeling of multiple longshore bars and their interactions, Coastal Engineering, 48 (3), pp. 151-170. https://doi.org/10.1016/S0378-3839(03)00024-3

[29] Jamal, M. H.; Simmonds, D.; Magar, V. 2014: Modelling gravel beach dynamics with XBeach, Coastal Engineering, 89, pp. 20-29. https://doi.org/10.1016/j.coastaleng.2014.03.006

[30] Pedrozo-Acuna, A.; Simmonds, D.; Otta, A. K.; Chadwick, A. J. 2006: On the cross-shore profile change of gravel beaches, Coastal Engineering, 53 (4), pp. 335-347. https://doi.org/10.1016/i.coastaleng.2005.10.019

[31] Williams, J.; de Alegría-Arzaburu, A. R.; McCall, R. T.; van Dongeren, A. 2012: Modelling gravel barrier profile response to combinedwaves and tides using XBeach: laboratory and field results, Coastal Engineering, 63, pp. 62-80. https://doi.org/10.1016/i.coastaleng.2011.12.010

[32] US Army Corps of Engineers 1984: Shore Protection Manual, Coastal Engineering Research Centre.

[33] Kamphuis, J. W. 1991: Alongshore sediment transport rate, Journal of Waterway, Port, Coastal and Ocean Engineering, 117 (6), pp. 624-640. https://doi.org/10.1061/(ASCE)0733-950X(1991)117:6(624)

[34] Van Wellen, E.; Chadwick, A. J.; Mason, T. 2000: A review and assessment of longshore sediment transport equations for coarse-grained beaches, Coastal Engineering, 40 (3), pp. 243-275. https://doi.org/10.1016/S0378-3839(00)00031-4

[35] Lončar, G. et al. 2016: Numeričko modeliranje morfodinamike poprečnog profila na šljunčanom žalu Medveja, Hrvatske vode, 24 (95), pp. 29-38.

[36] Battjes, J. A.; Janssen J. P. F. M. 1978: Energy loss and set-up due to breaking of random eaves, In Proceedings of the 16th International Conference on Coastal Engineering, Hamburg, Germany, pp. 569-587. https://doi.org/10.1061/9780872621909.034

[37] Doering, J. C.; Bowen, A. J. 1995: Parametrization of orbital velocity asymmetries of shoaling and breaking waves using bispectral analysis, Coastal engineering, 26 (1-2), pp.15-33. https://doi.org/10.1016/03783839(95)00007-X

[38] Isobe, M.; Horikawa, K. 1982: Study on water particle velocities of shoaling and breaking waves, Coastal Engineering in Japan, 25 (1), pp. 109-123. https://doi.org/10.1080/05785634.1982.11924340

[39] Dally, W. R.; Brown, C. A. 1995: A modeling and investigation of the breaking wave roller with application to cross-shore currents, Journal of geophysical research, 100 (C12), pp. 24783-24883. https://doi.org/10.1029/95JC02868

[40] Fredsoe, J. 1984: The turbulent boundary layer in combined wave-current motion, Journal of Hydraulic Engineering, 110 (8), pp. 1103-1120. https://doi.org/10.1061/(ASCE)0733-9429(1984)110:8(1103)

[41] Elfrink, B. et al. 1996: Modelling of 3D Sediment Transport in the Surf Zone, In Proceedings of the 25th International Conference on Coastal Engineering, Orlando, USA, pp. 3805-3817. https://doi.org/10.1061/9780784402429.294 
[42] Deigaard, R.; Fredsoe, J.; Hedegaard, I. B. 1986: Mathematical Model for Littoral Drift, Journal of Waterway, Port, Coastal and Ocean Engineering, 112 (3), pp. 351-369. https://doi.org/10.1061/(ASCE)0733950X(1986)112:3(351)

[43] Fredsoe, J.; Deigaard, R. 1992: Mechanics of Coastal Sediment Transport, Advanced Series on Ocean Engineering, 3, World Scientific Publishing Co., Singapore.

[44] MIKE powered by DHI, 2017: MIKE 21 \& MIKE 3 Flow Model FM, Sand Transport Module, Scientific Documentation, Available at: https://manuals.mikepoweredbydhi.help/2017/Coast_and_Sea/MIKE_FM_ST_Scientific_Doc.pdf Accessed 02 April 2021

[45] Zyserman, J. A.; Fredsoe, J. 1996: Validation of a deterministic sediment transport model for sheet-flow conditions, Progress Report 76., Institute of Hydrodynamics and hydraulic Engineering, Technical University of Denmark, pp. 1-7.

[46] Hijum, E.; Pilarczyk, K. W. 1982: Equilibrium profile and longshore transport of coarse material under regular and irregular Wave attack, Publication No. 274, Delft Hydraulics, Delft, Netherlands

Please cite this article as: Lončar, G., Kalinić, F., Carević, D., Bujak, D.: Numerical modelling of morphodynamics of the Ploče gravel beach in Rijeka, Electronic Journal of the Faculty of Civil Engineering Osijek-e-GFOS, 2021, 23, pp. 33-48, https://doi.org/10.13167/2021.23.4 